\title{
0189 YOUTH:RISK? MORE SAFETY FOR YOUNG PEOPLE BY RISK COMPETENCE LEARNING - FROM CONCEPT TO IMPLEMENTATION
}

U Loewe, ${ }^{*}$ E Braun Correspondence: Austrian Road Safety Board (Kfv), Schleiergasse 181100 Wien 1100, Austria

10.1136/ip.2010.029215.189

Risky behaviour is fun, but it may harm.

Description The AdRisk project Community action on adolescents and injury risk (EU Public Health Programme) has delivered recommendations and good practices on risk competence development in young people.

Results Individual risk competence can be developed by promoting special competencies and life skills concerning resilience to group/media/social influences. Risk competence has several components (1) adequate perception of situations, to realise the own mental and physical state, (2) assessment of risk and dangers, capacity also to develop alternative behaviours, (3) competence to act: responsible decision making for one self and for the group, (4) reflection of experiences, integration of former experiences (break), transfer to other situations. The aim is not to minimise the risk taking behaviour of young people but to balance the risk and to avoid harm. Also societal and strategic frame conditions are needed: establishing an ethos of risk competence development in teachers training, curricula development etc.

Implementation Methods and tools have been tested in different countries (eg, the Netherlands, Austria, Italy, Hungary). Factors for success are as follows: - Active participation of youth in the development of the measure - Understanding of the developmental need of risk taking - Focus peer group approaches - Using experience-based learning methods.

Recommendations It is important to identify the short- and long-term benefits of maintaining safe and healthy behaviour and of modifying behaviour that is harmful to health. Risk competence development is one successful approach (www. adrisk.eu.com). 